\title{
LAND RECORDS INFORMATION MANAGEMENT SYSTEM
}

\author{
Mr. Hira Gopal Maharjan
}

\begin{abstract}
Keywords: e-Government, Land Information System, Land Records Information Management System, Architecture, Service Delivery.

Abstract: The land administration services are being provided using traditional methods and processes. The record keeping system is mainly based on manual system so far. There is increasing need for efficient and effective delivery of land administration services. Government organizations use Information and Communication Technology to increase efficiency and effectiveness in the service delivery. E-Government can bring improvement in efficiency, easy availability and accessibility of service and information to the citizens, business organization, professional users as well as government organizations. The main aim of LRIMS is to automate the land transaction related functions of Land Revenue Offices (LROs) based on different land transactions process requirements.
\end{abstract}

The system is adherence to NeGIF and GEA, availability of intranet facility, provision of web-based system, and data security. System modules show the modules needed for LIS. The implementation status of LIS in Nepal is in initial stage. The old system architecture does not support the e-Government model. The system modules show the modules needed for LRIMS. The system modules help in delivering service efficiently. The three tier system architecture follows all three models of e-Government (G2G, G2B and G2C) and reduces corruption, increase access to information and improve data quality.

\section{BACKGROUND}

The Land Information System (LIS) history of Nepal is more than a two decade long. The first LIS was Integrated Land Information System Project 'Bhu Laxmi', which was developed in 1991/92 but could not function in practice for long time. The different application software were found that are used by LRO, SO and other organizations are discussed DLIS (District Land Information System, SAEx (Spatial Application Extension), Plot Register Management System (PRMS), Image Reference Management System (IRMS), Parcel Editor, OSCAR (Open Source Cadastre and Registration) SOLA Project. Regarding LIS Implementation Status, the data entry of DLIS has been started since F.Y. 2057/58 and consequently all the LRO's data have been digitized except Achham LRO likewise geo-database preparation in SAEx has been started since F.Y. 2066/67 and consequently all SO's geo-database have been prepared except Achham and Arghakhanchi districts. According to "Doing Business Report, 2015", Nepal's land registration is ranked at $27^{\text {th }}$ out of 189 countries and $1^{\text {st }}$ in South Asia and even $1^{\text {st }}$ in top ten services provided within our country

\section{INTRODUCTION}

It is an ADB granted ICT Development Project, one of the components of e-Government applications under Office of Prime Minister and Council of Ministers of US \$ 1.365 million. It was started in April 28, 2013 A.D. and will end in May 2018 A.D. (including Post Warranty Service). It is a web-based software solution developed and installed in Government Integrated Data Center (GIDC) under Government Enterprise Architecture (GEA) and Nepal e-Government Interoperability Framework (NeGIF). This will meet the needs of the Department of Land Reform and Management (DOLRM), Land Revenue Offices (LROs) and other stakeholders. DOLRM, LROs and other stakeholders will access the application via WAN within Intranet. It covers Non-spatial data at LROs only. The main aim of the project is to implement web-based centralized system in GIDC \& DOLRM for automating the 14 LROs activities. The project sites are DOLRM, 14 LROs (Baglung, Banke, Bhaktapur, Biratnagar- Morang, Chabahil, Chitwan, Dhading, Dillibazar, Kalanki, Kaski, Kavre, Lalitpur, Makawanpur and Parsa).

\section{OBJECTIVE}

- To automate the land transaction related functions of Land Revenue Offices (LROs) based on different land transactions process requirements.

- To make the information easily accessible to land owners and related authorities.

\section{SYSTEM ARCHITECTURE OF LRIMS}

The system architecture of LRIMS is designed with the concept of three architecture:-One application Server, one web server and core based partitioned database server hosted in GIDC. The backup servers 
for application server and database server are also maintained. It is web based and centralized system. The 14 LROs are connected to the central database. This architecture consists of three layers:

Presentation Layer: This layer contains the user oriented functionality responsible for managing users' interactions with the system and consists of components that provide a common bridge into the core business logic encapsulated in the business layer. This layer comprises of user interface (that includes styling and scripting resources). This layer is responsible for gathering inputs from the user and passing the same to the business layer for processing. The presentation layer ensures that the communications passing through are in the appropriate form for the recipient business objects in the business tier. To access the system, the user will connect via intranet and need to get authenticated by the security subsystem of the application (firewall). Based on his/her role, the user will be shown the modules for which he/she is authorized. The system will provide the common front-end for all the modules.

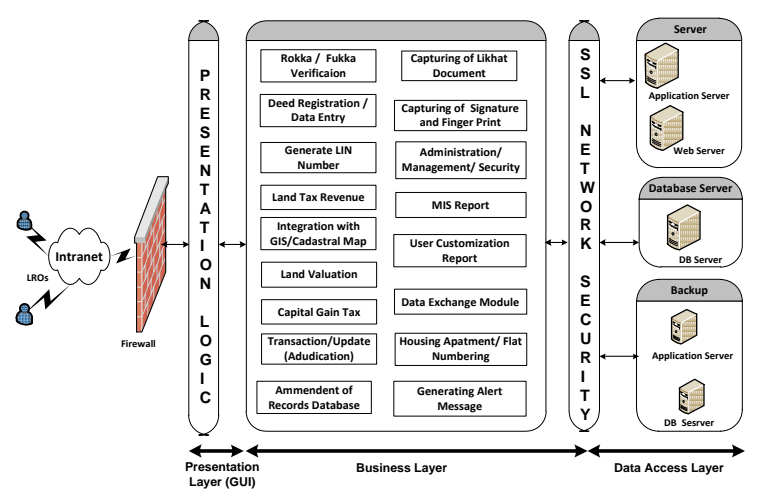

Figure 1.1: System Architecture of LRIMS

Business Layer: This layer implements the core functionality of the system and encapsulates the relevant business logic for rokka fukuwa verification, deed registration/ data entry, unique LIN number, land tax revenue, integration with GIS/Cadastral map, land valuation, capital gain tax, transaction/update(adjudication), amendment of records, capturing likhat document, capturing signature and finger prints, administration/management/security, MIS reports, user customization report, data exchange for various applications, housing apartment/flat numbering and generating alert message modules. It consists of components which may expose service interfaces that other callers can use.

Data Access Layer: This layer provides access to data hosted within the boundaries of GIDC and data exposed by other networked systems; perhaps accessed through services. The data layer will expose generic interfaces that the components in the business layer can consume. It handles the translation from data in its native format, such as SQL tables or XML elements, to a form more suitable for the business logic tier, such as objects. It consists of application, web server and database server. There are backup servers for all the servers in standby condition so that if one fails other will take over. There is SSL network security to protect from unauthorized access to server and database.The system modules of LRIMS are as follows:

\section{Rokka/ Fukka Verification}

This is a restriction and release of land transaction implemented by district offices on request from agencies like banks, CIAA, court, government decision. Traceable to 'Dohoro Darta' needed to be recorded for necessary action.

\section{Deed Registration / Data Entry}

The Deed Registration is capturing of land records maintained in LROs. It is a process of transferring ownership rights of a land parcel / building from one owner to another due to sale / purchase of land by one owner to another. This module entries/captures/updates records originating in LRO such as Deeds, 'New Land Records,' etc.

\section{Generate LIN Number}

The module generates unique Landowner's Identification Number (LIN) for finding records. LIN code is similar to Personal Identification Number index to locate/find the records and is generated with the key combination of date of birth, district code, $\mathrm{s} / \mathrm{n}$, gender, calculated result of special formula etc.

\section{Land Tax Revenue}

The module records tax revenue levied to each land record. It also shows tax amount to be paid by the land owner plus delay charges, rebates and produce receipt of payment and report about the status of revenue.

\section{Integration with GIS/Cadastral map}

The module integrates with GIS/Cadastral map information and produce comprehensive information. It should be possible to link with the National Geographic Information System (NGIS) in future.

\section{Land Valuation}

Land Valuation is the process of calculating land value as per specific circle rate for different land areas. The module enters land value and produce land/property valuation report.

\section{Capital Gain Tax}

The module calculates capital gain tax according to conditions for Deed Registration process.

\section{Transaction/Update (Adjudication)}

There are various types of transactions or Deeds, such as 'Rajinama', 'Hal Ko Bakaspatra', 'DanPatra', 'Chhod Patra', 'Sagol Naama', 'Ansha Banda', 'Chhut 
Darta', 'Bejilla Da Kha', 'DaKha by Auction', 'Purano Dakha' etc. The module performs transactions on the different types of transaction.

\section{Amendment of Records}

The module handles amendment of records by application request such as 'samsodhan' / 'namasari' or other related tasks.

\section{Capturing Likthat document}

The module captures "Likhat", "Tameli" data etc.

\section{Capturing Signature and Finger Print}

The module captures and store the signature and finger prints wherever applicable.

\section{Administration / Management / Security Module}

The module administers and manages various levels of users and different types of security. It also manages parameters (Zone, District, VDC codes, land types, etc.). It will also have Audit Trail System.

\section{MIS reports}

The module provides various types of MIS reports required for the different levels of management (LAOs, Central level). The module will also be able to query information by different criteria available in database.

For District Level

- Information Query on Current status of Parcel

- Information Query on Land Holding against Land Holding Ceiling

- Daily Revenue Collection Report

- Monthly Progress Report

- Parcel History Report

- 'Sresta' Reproduction (printing)

- Annual Land Revenue 'Lagat'

- Tenants status

Central Level MIS report

- Land ceiling

- Gender wise , Administrative unit wise (i.e. VDC wise, district wise, ward wise)

- Land size, type, class, ownership share

- Total private, public and government land

\section{User Customization Report}

The module provides different end-user customization reports.

\section{Data Exchange for various applications}

The module generates data to exchange between other applications such as NID, IRD, Muncipality, Bank etc.

\section{Housing Apartment/Flat Numbering Module} related transactions.

\section{Generating Alert Message}

This module generates an alert message and forward it to the concerned citizens address (email, mobile etc.) while performing any kind of transaction. It will also have functionality of query reply when query is performed through SMS.

\section{SYSTEM DESIGN ARCHITECTURE FOR IMPLEMENTATION}

The system design architecture for implementation is depicted in the figure below:

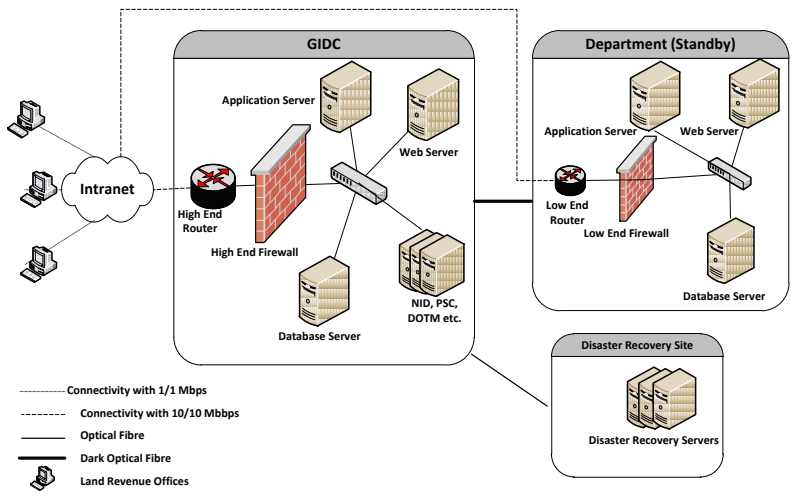

Figure 1.2: System Design Architecture for Implementation

The System Design Architecture connects all the LROs to the centre office and the GIDC which is established for the integration of government database. The LROs connecting to the application over intranet link using browser are authenticated before allowing connections. The web, application and database servers are stored by the GIDC i.e. DC sit. There will be Standby site in department which is the exact replica of the system in GIDC. All the changes in GIDC system will automatically be saved in Standby system in department.

The servers are RISC based IBM machines. The web server will be in redundant configuration by means of dual power supply and raid array configuration to avoid the failure of server. The system will independently work and will ensure continuous running of the web services. The RAID 6 configuration has advantage over RAID 5 will be preferred here to better. The RAID 6 is configured for better redundancy and data protection. RAID 6 can protect mission-critical data from two concurrent disk drive failures. The application server will have similar setup to that of web server. This is middle tier in the setup architecture and used for application installations. These servers have AIX operating system. The servers will be part of local area network and placed behind the firewall. The web server communicates with this middle tier application server for functioning of entire application. Port based secured communication is allowed using firewall for enhanced security. The database is Oracle $11 \mathrm{~g}$. This is the third tier and part of LAN. The web, application server and database servers are kept in LAN for preventing from hacking and for 
better security. For data security the servers have iptables as firewall and there is also a high end firewall for more security. The technologies like cryptography, PKI, digital signature are used for security purposes.

All the LROs access through the application at the GIDC. The users connect the web server which is kept in intranet via the intranet link. The web server will communicate with application server and database server which are kept in LAN. The GIDC has dual high connectivity internet link and dual electrical feeder. The connectivity of LROs with GIDC is via $1 / 1 \mathrm{Mbps}$ intranet link. The connectivity of department to GIDC is dual. The primary link is dark optical fiber and secondary link is $10 / 10 \mathrm{Mbps}$ dedicated optical fiber intranet link for continuous data replication to occur in the severs located at department. However, this connectivity is only for the initial stage and will be increased in future. The concept of DR site for whole GIDC has also been initiated and feasibility study for this has been done and proposed for Hetauda DR site with the aid from KOICA. So, the system will have high availability.

The GIDC will be connected to disaster recovery and the backup of all the servers in GIDC will be maintained in disaster recovery site. There is high end firewall for the authentication process in GIDC and low end firewall in department. The web interface will feature single sign on and authentication system to prevent unauthorized access.

If the system in GIDC fails, the standby system in department will take over the system. It is designed in such a way that the entire setup will be located in a central location and the data will be accessed over the intranet link from anywhere, the entire solution is web based thus providing unhindered accessibility and ease of use.

\section{WORKING PROCEDURE OF LRIMS APPLICATION}

The working procedure of LRIMS application is as follows:

- Super Administrator: Manage the overall system

- Local Administrator: User Management, Valuation Mgmt. \& Report Generation etc.

- Service Desk: Form fill up, upload document, photo, thumb \& signature capture and form submission.

- Junior Officer: Verify the form contents with attached document including online verification, issue letter for parcel split, public notice, collects revenue if no bank is available, generate LOC etc.

- Bank Officer: Cash in and receive revenue. Submit collection report to LRO
- Land Revenue Officer: Verify and approve the application/form, forward application/form to CLRO / backward to lower level

Chief Land Revenue Officer: Verify and approve the application/form, forward application/form to DOLRM for suggestion / backward to lower level

\section{FEATURES OF LRIMS APPLICATION:}

- The Front-end (Programming Language) is in Java.

- A web based application based on GEA (Government Enterprise Architecture ), SOA and NeGIF (Nepal e-Government Interoperability Framework)

- Bilingual-Developed in English and Nepali (Unicode)

- Centralized system and standby backup (DOLRM and GIDC)

- 24x7 (24 hours, 7 days a week) service availability

- Accessible throughout the worldwideweb (www.nepal.gov.np) and a land owner can check his/her application status, own property details and can lodge application from own place in future

- An application can be lodged into a LRO from other service desk/center for a transaction (Bejilla)

- Secure (Thumb verification, Photo \& Signature capture, User \& Password) and transparent transaction maintaining history of each activity

- Automation of functions of LROs, Land Reform offices and Guthi offices making working procedure uniform throughout the country

- Introduction of paper less system

- Automatic valuation \& tax management

- Provide an Integrated Land Ownership Certificate (LOC).

- Land ceiling and Rokka can be automatically verified by system

- Generation of different types of LIN, LOC and different types of Reports

- Alert message to the registered mobile/email.

- Fields of forms are configurable (Mandatory and Optional)

- Provision for online validation of thumb impression, password, land parcel no., NID, PAN etc.

\section{COMPARISON OF OLD SYSTEM AND LRIMS ARCHITECTURE}

Table 1.1: Comparison of old system and LRIMS Architecture

\begin{tabular}{|l|l|c|c|}
\hline S.N. & Parameters & $\begin{array}{c}\text { Old System } \\
\text { Architect } \\
\text { ure }\end{array}$ & $\begin{array}{c}\text { LRIMS } \\
\text { Architectur } \\
\text { e }\end{array}$ \\
\hline 1. & Architecture & $\begin{array}{c}\text { Client server } \\
(2 \\
\text { tiered) }\end{array}$ & 3-tiered \\
\hline
\end{tabular}




\begin{tabular}{|c|c|c|c|}
\hline 2. & $\begin{array}{cr}\text { Adherence } & \text { to } \\
\text { NeGIF and } \\
\text { GEA }\end{array}$ & No & Yes \\
\hline 3. & Centralized & Stand alone & Centralized \\
\hline 4. & Web based system & No & Yes \\
\hline 5. & Integrated LIS & No & Yes \\
\hline 6. & Data security & Low & High \\
\hline 7. & $\begin{array}{r}\text { Duplication of } \\
\text { Records }\end{array}$ & High & No \\
\hline 8. & Electronic services & $\begin{array}{c}\text { Do not } \\
\text { support }\end{array}$ & Supports \\
\hline 9. & $\begin{array}{l}\text { Chances of theft, } \\
\text { Fire, Natural } \\
\text { Disaster }\end{array}$ & Always & Rare \\
\hline 10. & Interoperable & No & Yes \\
\hline 11. & Availability & Low & High \\
\hline
\end{tabular}

Table 1.1 describes about the comparison of old system and LRIMS architecture. The comparison is done on the basis of 11 parameters viz. architecture, adherence to NeGIF and GEA, centralized, web based system, integrated LIS, data security, duplication of records, electronic services, theft, fire $\&$ natural disaster, interoperable and availability. In case of architecture, the old system is 2-tiered but LRIMS is 3-tiered architecture. The LRIMS is compatible with GEA standard and NeGIF but the old system is not compatible with GEA standards and NeGIF. The old system is standalone system with separate server for different offices while the LRIMS is centralized so that the whole system can be controlled by one location and management of server and database is easy.

The LRIMS is web based and it can be accessed from anywhere via intranet but the old system can be accessed by concerned office only. The data security is high in LRIMS as it uses Oracle database but old system uses MS-SQL and MS-Access. There is more duplicate data in old system as it does not have unique LIN but there is provision of unique LIN in LRIMS so there will be no duplication of data. The flow of information takes place through electronic media in LRIMS and supports digital signature. But the old system does not support electronic services. There is always chance of theft, fire \& natural disaster in old system as it is located in the local office but less chance of theft, fire \& natural disaster in LRIMS as it is located in GIDC where there is good physical security, facility system like leakage detection system, firefighting system etc. The old system is not interoperable with other system as it is standalone and not compatible with GEA and NeGIF but the LRIMS is interoperable with other systems. The LRIMS system has high availability as the system is centrally located in GIDC where there is dual power system with UPS and generator, dual high speed internet connectivity, and the exact replica of the system is also installed in department and the disaster recovery site for GIDC will be established soon in Hetauda. There is also backup server for the application and database server itself in GIDC. If one server gets crashed other server will take over. Likewise if the GIDC system fails, the system will automatically take over by the standby system located in department. So, there is high availability in LRIMS.

\section{BENEFITS}

\section{i.To Citizens:}

- 24 x 7 (24 hours, 7 days a week) service availability

- Economical (Labor, Time \& Cost), Transparent, Equitable and Convenience

- Fast and efficient service

- Can get an integrated LOC from any LRO.

ii. To Government:

- Centralized LIS database

- Correct and up to-date land information for better policy making and regulatory and development functions

- Very fast acquisition, storage and retrieval of data leading to better decision-making

- Protect the information from disaster like fire, earthquake etc.

- Better management of land administrative functions/processes - uniformity

- Better performance in regulatory functions like taxation, valuation, land use etc.

- Protect unauthorized transaction of Personal, Government \& Public land

- Capture land ceiling land

- Helpful to reduce land disputes and to make officials and landowner accountable

- Protect officials- Maintains history of each activity

- Helpful for supervision and monitoring of the work from Centre

- Creates the positive image of modern and progressive land administration.

iii. To Stakeholders:

- Get correct information on time

\section{LIMITATIONS}

The map related data i.e. spatial component is not included in this system but this system has provision of one module that can integrate with GIS/ Cadastral maps in future. Currently the parcel splitting trace is scanned and uploaded in the system.

\section{References:}

Dangol, S. (2012). e-Government Based Land Information System Architecture : A Case of Nepal. Enschede, the Netherlands.

DB, (2015) Comparing Business Regulations for Domestic Firms in 189 Economies. Doing Business 
2015 (12 $2^{\text {th }}$ edition). A World Bank Group Flagship Report.

DOLIA, (2015) Implementation status of DLIS and SAEx. LIS Analysis and Coordination Section, 2015.

Maharjan, H.G. (2014) Designing Land Information System Architecture and module for Nepal, Purbanchal University, 2014.

Sah, S. (2015) Presentation on Online Service in Land Administration. Paper presented at Land Administration Workshop, Baneshwor, Nepal.

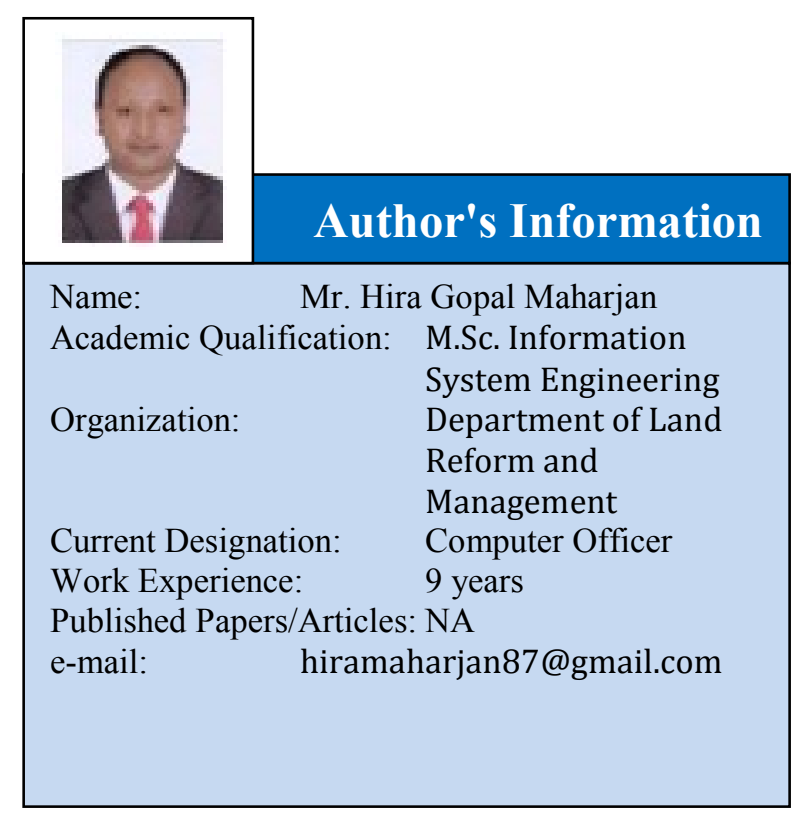

